\title{
The Emotional Intelligence in IT Employee's
}

\author{
Sajan Vaidhyanathan Shanker, Jahira Parveen
}

\begin{abstract}
In the quest to develop leaders who will foster a culture of equity and inclusion in the workplace, a critical factor to assess is Emotional Intelligence. EI (Emotional Intelligence) is a way for us to recognize our emotions as well as the emotions of other people. Individuals who are high in EI can recognize the emotions of others and are able to convey and regulate their own emotions. At organizations, work pressure, strain, anxiety, fearfulness, angstand depression are all related to Emotional Intelligence. These emotions could affect a person's performance at workstation. Emotions can impact a performance, they can either create a high or crash the employee's morale which will affect the persons performance positively or negatively. The research paper casts light upon the measurement of EI, and how it impacts an employee's performance. The highlights the job performance, the importance of performance index.
\end{abstract}

The main purpose of the research analysis is to understand the effectivenessEIin IT(Service Sector), and how it influences their performances. The research methodology used in the study is a hybrid approach that consists of exploratory and descriptive research methods. The exploratory research is considered as the primary research method, while the descriptive research method is considered as the secondary data.

We will analyze the relationship between dependent variable and independent variables of factors affecting the development of emotional intelligence of employees. This research is conducted in IT organizations in Chennai, for feasibility purpose.

\section{Index Terms: Morale, Performance, Challenges, Intelligence}

\section{EMOTIONAL INTELLIGENCE}

Many Researchers have identified that there is an emotional side in the human brain from where allthe emotions originate. It is not linked to the rational thinking part of the brain brain but they both develop together as we age on. The term Emotional Intelligence (EI) was used for the first time in 1985 from Payne and was considered to indicates person's ability torelate to fear, pain and desire. EI is how one manages emotional cases.Sometimes certain employees tend to overreact in difficult situations and regret about it later. These overreactions can lead to the arousal of conflicts and controversies.

To illustrate EI, you ought to questionyourself: How do you connect with yourself and with people around you? Your

Revised Manuscript Received on July 05, 2019

Sajan Vaidhyanathan Shanker, Marketing Operations Specialist, SysArcInfomatix.

Dr. Jahira Parveen, Faculty of Management, SRM Institute of Technology, Chennai. his/her activities with oneself and others during strong

ability to know andmanage your emotions for yourown good as well as everyone around you is considered as EI.

Many literatures and research papers have defined EI in different ways. But they all seem to be centered upon a common theme, which is our ability to recognize our emotions and how we manage them, to maintain for harmony in our personal and professional life.

\section{REVIEW OF LITERATURE}

Deepa. R (2009), in her work states that EI is how we manage our emotions and people's emotions. This work has helped researchers, as it signifies the impact of EI on personal and professional success of every individual. This work also proves that EI has an impact on performance and characteristics of each individuals.

Krishnaveni.R and Deepa.R (2008), They talk about deadlines, team work, stressful situations and personal conflicts and how it affects the workforce. These circumstances can have a gloomy impact on the employee's performance and contribution to the organization's success. This research paper explains how EI can help to enhance abilities which would help organizations gain competitive advantage over their rivals.

Dulewicz and Higgs (1998), in reference to their work point out that people with high EI have more successful careers. Weisingeralso suggests the same. Jordan et al research states that those with high EI feel less stressed about their job and focus on succeeding. Cooper and Sawafstate that people with higher EI can lead the organization more effectively than the rest. Rice concludes that people with high EI are more adaptable to changing circumstances and their teams perform exceptionally.

Gunavathy and Ayswaryaresearch work on EI and its impact on Job performance, on a sample of 150 test subjects, state that; high EI has a positive impact on employees' performance and their satisfaction. They advise to engage in more interactive effort as EI of a person always improves and more over to keep the employees motivated and satisfied more recreational activities should be done.

Yu-ChiWu in his finding concludes that recruiting higher Emotionally Intelligent people can have a constructive impact on the organization's success.

\section{THEORETICAL FRAMEWORK}

Foundations of EI:

Let's have a look at the foundational elements that are the bedrock of Emotional Intelligence

Motivation: Head of departments/managers/seniors are determined to get the work done. Leaders with higher EI 
are more likely to understand and are resistant to both success and failure. They're driven by strong motivation to achieve and not merely by titles or money

Self-Awareness: People who have high sense of self-awareness are "confident on their own abilities." They have a clear view on their strengths and weaknesses. They understand how to keep their emotions in check as it could have impact on others. The most important pointer to note for is their ability to respond to criticisms, shows a great deal about their self-awareness.

Self-Portraying: People with high EI also feel the same exuberance and disappointment like all of us. What separates them from the rest is they know how to portray their emotions, so that it wouldn't affect the rest. They don't quash their emotions, but they express it in a more controlled and constructive way.

Empathy: One of the important skills that high EI manager possesses is empathy. The care and understanding that connects them to the team emotionally. Empathy allows them to have a stellar impact with the team and obtain success

Management Skills: Leads with high EI are widely respected by their peers and team. They can easily understand the requirement and know what resources to allocate and can get the best out of their team. They would have a stock ability to trust with the team. They do not engage on backstabbing, deception and will always stick to their word.

A representation on how impacts the performance of IT Employees:

In usual standards a person with a high level of EI fares better in personal and profession life, EI improves the life of an individual.

\section{How EI impacts at Workstations:}

EI enables people to think out of the box to solve the issues that arise. To be successful in profession, the important factors people need to use are their EI along with technical skills, social, communication and knowledge. A key aspect of EI is a person's ability to manage his/her feelings while being stressed out. The ability to control outbursts and emotions can lead to a more successful professional and social life.

One of the most important traits of a great leader is the procession of high Emotional Intelligence, because he/she is the one who manages the entire moral of the team or organization. The leader should be aware and more empathetic to understand what's happening in the organization and should motivate the team by understanding their emotional state.

Emotionalintelligencewillbedifferentforvarioustypesoflea ders.Forexample, "That's what we pay you for" is one of the arguments that a leader should avoid in workstation. Thesetypes of emotional outbursts should be kept undercheck,decisions should be based on facts, information and analysis.Emotional outbursts could affect the performance of a normal employee by making them lose motivation, detached from the team or management and feeling more insecure, which could more or less result in failure to be productive for the organization. This is not a good sign for any organization, bad leaders could have negative impact on their team, which will cause pessimistic behavior and being around these types of people could be very exhausting for a normal person. So hence, developing EI in a workstation is always useful, as it helps people to become more productive, which in turn they can handle these types of emotional outbursts from others in a more positive and constructive manner. It is very important to have a good leader with a high EI level, as he has more positive impact on the entire workforce than a bad one.

\section{How Stress impacts at Workstations:}

The challenge the workforce worldwide faces us stress. Stress of two types, it can be personal stress and professional stress, both could lead to the employee contributing less than optimal output. The personal stress is the one that arises from the employee's personal life. A high EI helps employee's is to manage certain outbursts and emotions, so that it doesn't affect them and their performance at workstation. The other type of stress is work related stress that arises from the work, it occurs when employees work and pressure is out of proportion, the work does not match with their knowledge or it may be far beyond their abilities, it's a huge challenge for the employees to cope up with them.

Stress that arises from the mismatch between employee's skill set and demand of the organization, which might be out of the employee's scope of work. It's a huge challenge on the employee to cope with the work and to produce result. There will be situations where work pressureexceeds the ability and knowledge of the employee, which would cause stress to raise, it creates a big problem in itself. Then employee would start to feel the pressure, due to workload, deadlines and targets that need to be achieved. If the employee has a bad relationship with the boss, it could directly impact the work and will also create an additional level of stress. This would directly contribute to high attrition rate and less productivity in the organization. Stress at workstations may also occur due to wide range of circumstances at the organization, what makes things even worse is if they get little to no support from their leads or heads.

To prevent stress at workstation, there ought to be a healthy and happy work environment. If an employee feels stressed out then the manage should come to his/her aid. Normally managers cannot protect employee's health outside the organization, but a little empathy can go a long way in motivating the employee.

How stress affectshealth and performance at workstations:

EI plays a huge role in handling stress at workstations, how stress impacts health and performance at workstations was investigated. High work pressure leads to more stress and it has a direct impact on health and performance of employee at workstation. High stress could lead health issues such as anxiety, insomnia and depression. The performance also dips.

Stress doesn't impact everyone the very same. Everyone has a different way of coping up to stress, some people are torn to shreds at the slightest provocation. Some people are destructible in high stressful conditions and they become even more successful, in these situations our Emotional Intelligence (EI) aid and guide us to be successful. High EI level will you to cope up with stressful conditions. But EI also varies from person to person and depends upon how each individual manages a potential stress condition and reacts to it.

\section{METHODOLOGY}

The research involves more systematic structure of investigation, which usually 
results in some formal record of procedures and the report of the results.

\section{Research design:}

The study is mainly a descriptive research designed to know the reason for emotional intelligence of IT Employee's.

\section{Tools for data collection:}

Primary source of data was collected with distribution of questionnaire to IT Organizations. We have used two method for distribution of questionnaire, direct distribution respectively soft copy of questionnaire was sent to private and public organization and we have asked to fill the question with email distribution. So, we have sent questionnaire in English.

\section{Study location:}

This study was conducted with employees of select industries at Chennai, Tamil Nadu under various IT Organizations.

\section{Sampling:}

Since the universe of the study is infinite, convenient sampling has been used. The sample covered different occupation of employees at workstation. Totally about respondents were selected for the purpose of collection of data.

\section{Objectives of the study:}

This study is an effort to find out the vital role of emotional intelligence in IT employees at workstation and the objectives of this study are below:

To investigate the role of emotional intelligence in stress management among IT employees at workplace

To find out what causes stress at workplace

To uncover the impact of emotional intelligence on performance of employees under stressful conditions

\section{Emotional Intelligence of IT EmployeesResult:}

According to our questionnaire; the first part of our result is used to dedicated the level of Emotional Intelligence of respondent. This part includes 5 questions; the point gained from each question is in range from 1 to 5 point based on the answer. The minimum level of Emotional Intelligence if the respondent answered all the questions with 1 point is 15 and the maximum level of Emotional intelligence if the respondent answered all the question with 5 point is 75 .

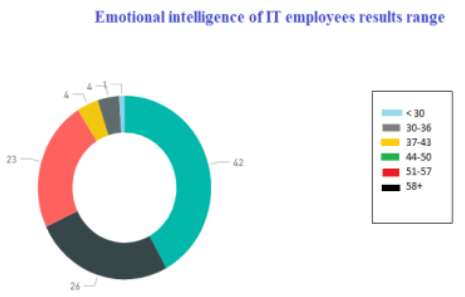

The research result for emotional intelligence of IT employees index have been grouped in 6 groups (Figure 1). The first group covers the respondent which level of Emotional Intelligence is less than 30 point which is the lowest level. From below graphs we see that in this group belong $1 \%$ of respondent, respectively 2 out of 252 respondents. The second group has 10 respondents respectively hovers around $4 \%$. The third group has 62 respondents which respectively hovers around $23 \%$. The range group $44-50$ has 100 which is $28 \%$ of all. The next group from 51 to 57 , includes 68 respondents respectively 26 $\%$. And the last group which incorporates from $58-60$ includes 10 respondents or $4 \%$.

How EI plays a key factor in IT Employee's Performance:

To measure the performance of employees we have asked 8 questions, and with the answers we have formulated the index depending on the value of each question. The minimum index is 10 if in all questions the respondents will take the minimum results, and the maximum index is 80 if respondents will take the maximum results. The results we have grouped into 5 groups where we have this overview (Figure2):

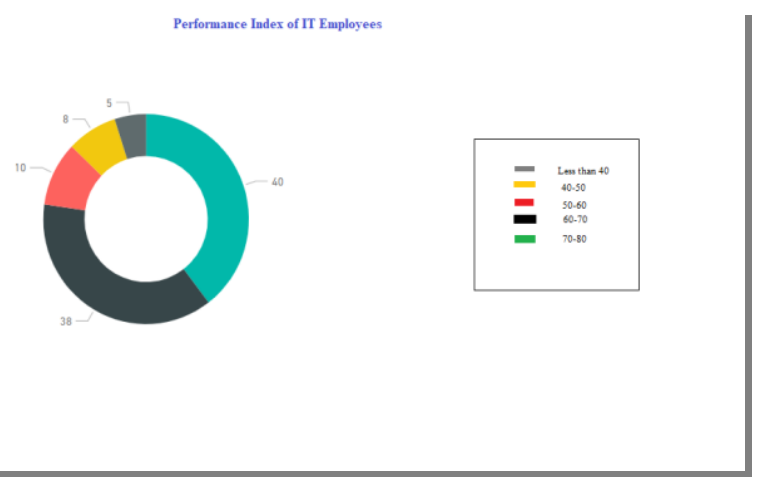

This part of questionnaire is dedicated only to employee 's questionnaire only. As we can see the first group includes the index above 40 point and in this group we have around 10 employees. The second group between 40-50, here we have 20 employees or $8 \%$ from total 252 . The third group includes between 50 - 60 points and here we have 106 respondents or $40 \%$ from total. The fourth group includes points between 60 and 70 and here belong 94 respondents $38 \%$. Finally, in the last group we have the respondents with the highest points in working performance, where the results are 22 or $10 \%$ from total 252 .

\section{Hypothesis Testing:}

The research hypothesis of this research paper and variable description is:

$\mathrm{H}_{0}$ : Employees with high level of Emotional Intelligence in IT sector, achieves highest level ofperformance the regression variables are: Employee Performance, Emotional Intelligence and Dummy Age VariableDescription

(Dependent) Employee Working Performance, range value 1 to5.

(Independent) EQ Index, range value 1 to5.

(Independent) Dummy Age, 0 for employees younger than 30 years and 1 for employees older than 30years.

Regression analysis of Third Hypothesis 


\begin{tabular}{|l|l|l|l|l|}
\hline Model & $\mathrm{R}$ & R Square & $\begin{array}{l}\text { Adjusted R } \\
\text { Square }\end{array}$ & $\begin{array}{l}\text { Std. Error of } \\
\text { the Estimate }\end{array}$ \\
\hline 1 & $.496^{\mathrm{a}}$ & .246 & .239 & .27110 \\
\hline
\end{tabular}

a. Predictors: (Constant), DUMMYAGE, EQ1

$\mathrm{R}^{2}$ of regression is 0.246 shows that independent variables represent the dependent variable for $24.6 \%$ ANOVA $^{\mathrm{a}}$

\begin{tabular}{|l|l|l|ll|l|l|}
\hline \multicolumn{2}{|l|}{ Model } & Sum of Square & df & Mean Square & F & Sig. \\
\hline & Regression & 5.006 & 2 & 2.503 & 34.054 & $.000^{2}$ \\
\hline 1 & Residus1 & 15.361 & 209 & .073 & & \\
\hline & Tocal & 20.367 & 211 & & & \\
\hline
\end{tabular}

Dependent Variable:PERF1

Predictors: (Constant), DUMMYAGE,EQ1

The multi regression model is significant in $\mathrm{p}$ value 0.001 . The model form is:

Working Performance $=\beta_{0}+\beta_{1} E Q+\beta_{2}$ Dummy Age Coefficients $^{\mathrm{a}}$

\begin{tabular}{|c|c|c|c|c|c|}
\hline \multirow[t]{2}{*}{ Made1 } & \multicolumn{2}{|c|}{$\begin{array}{l}\text { Unstandardized } \\
\text { Coefficients }\end{array}$} & \multirow{2}{*}{\begin{tabular}{|l}
$\begin{array}{l}\text { Standardized } \\
\text { Coefficients }\end{array}$ \\
Beta
\end{tabular}} & \multirow[t]{2}{*}{$t$} & \multirow[t]{2}{*}{ Sig. } \\
\hline & $\mathrm{B}$ & Std. Err $\propto$ & & & \\
\hline (Constant) & 1.876 & 144 & & 13.000 & .000 \\
\hline EQI & .385 & .047 & 503 & 8.241 & .000 \\
\hline $\begin{array}{l}\text { DUMMMYA } \\
\text { GB }\end{array}$ & -.084 & .045 & -.116 & -1.896 & .059 \\
\hline
\end{tabular}

Dependent Variable:PERF1 RegressionModel

$\beta_{0}=1.876$

$\beta_{1}=0.385$

$\beta_{2}=-0.084$

Working Performance $=1.876+0.385$ EQ -0.084 Dummy Age

\section{Comments:}

Emotional Intelligence has an impact on working performance of employees in IT employees. Based on the result from multiple regression analysis coefficient $\beta_{1}=0.385$ shows that for 1 value increase in Emotional Intelligence index, the working performance index will be increased for The coefficient $\beta_{2}=-0.084$ from dummy age variable, shows that employees older than 40 years have shown less working performance than employees younger than 40 for coefficient 0.084 .

$\mathrm{R}^{2}$ of regression is 0.246 shows that independent variables represent the dependent variable for $24.6 \%$

We have positive correlation with positive coefficient of 0.481 which means that the Level of Emotional Intelligence of employees has positive impact and correlated with Working Performance of employees, coefficient is significant at level 0.01 .

\section{CONCLUSION}

Third hypothesis -The performance of employees depends from the level of Emotional Intelligencell is supported with positive correlation coefficient between working performance index and the level of Emotional Intelligence of employees. According to the results we can conclude that employees which have higher level of Emotional Intelligence are more successful on their work and have higher working performance index. The correlation coefficient between EQ index and working performance index is 0.481 and the effect of EQ over Working Performance declared with coefficient $\beta 1=0.385$ shows that for 1 value increase in Emotional Intelligence index, the working performance index will be increased for 0.385 the coefficient is significant on 0.001 level.

\section{RECOMMENDATION}

The purpose of the research was to identify the effect of Emotional Intelligence level of IT employees in Chennai over working performance and change initiative. Based on the results we would like to give below suggestion to all private and public organization:

- The organization need to increase awareness of Emotional Intelligence as an important factor which impacts the working performance. It is not important only educational degree, there is also educational grade or the level of IQ to ensure that the employee will have great working performance, and in order to have smarter employee it is also important the level of Emotional Intelligence as a psychologicalfactor.

- The most important fact is that the Level of Emotional Intelligence can be improved, and the company need to organize training and need to provide training materials from different literature regarding Emotional Intelligence and the importance of changes for any success in business

- The company need to build system for recruitment of future potential employee, with ensuring from the beginning that are going to hire the right person for the right position together with the right level of EQ where specific position may require.

\section{REFERENCES}

1. Deepa. R (2008), "Adpatation of emotional intelligence to Indian context", Sixth AIMS International Conference on Management, vol.40, iss.5, Pg626

2. Krishnaveni.R and Deepa.R (2008) Emotional intelligence - A soft tool for competitive advantage in Indian organisation", AIMS International Conference on Management, Greater Noida, vol 7, 8pgs.

3. Dulewicz, Vand Higgs, MJ (2000), -Emotionalintelligence: a review and evaluation studyll, Journal of ManagerialPsychology

4. Gunavathy J., Ayswarya R. (2011), Emotional Intelligence and Job Satisfaction as correlation of Job Performance - a study among women employed on Indian Software Industry.

5. Yu-Chi Wu (2011) Job Stress and Job Performance among employees in the Taiwanese Finance Sector: The role of Emotional Intelligence, Taiwan 